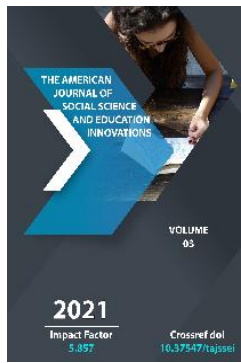

\title{
Ethnomadanian, Ethnoestetic Aspects Of The Formation Of A Healthy Lifestyle In Society
}

Siroj Madatovich Ruzimurodov

(PhD) Teacher Of The Department Of Philosophy And National Idea Samarkand State University Samarkand, Uzbekistan

Journal Website:

http://theamericanjour

nals.com/index.php/taj

ssei

Copyright: Original content from this work may be used under the terms of the creative commons attributes 4.0 licence.

\section{ABSTRACT}

In this article, the role of society and family in the harmonious upbringing of young people on the basis of ethnoesthetic factors of the formation of a healthy lifestyle in society is analyzed philosophically and aesthetically. There are also rich ethnomadani and ethnoesthetic traditions in Uzbek families.

\section{KEYWORDS}

Society, family, child, ethnomedaniac, ethnoestetic upbringing, spirituality, values, parent, neighborhood, tradition, aesthetic.

The problems associated with understanding a healthy lifestyle in society are becoming more relevant. From this point of view, the 
improvement of cities and villages in order to raise the life of our people to the appropriate lifestyle and level and to live at the same time depends on ethnoesthetic aspects. We are currently embarking on great practical work in this regard."Huge construction and landscaping work is being carried out on the basis of modern projects throughout the country. In this regard, especially the "prosperous village" program is important. This is primarily a program that has a huge impact on improving the living conditions of our women, elevating their mood, outlooktirishga[1-476].

The new criteria, the principles of living, the vitality of national ideology, ultimately the nature of our prosperous and healthy lifestyle, which we are finding in our country, give a concerted conclusion that it should be compatible with its psyche. On the other hand, a healthy lifestyle is not just a set of living principles, but also a complex process that always dictates the interaction of internal laws, contradictions and poles. Thanks to this, any needs and principles that are formed will be tested, perfected or, on the contrary, denied in the field of this style.Therefore, understanding a healthy and prosperous lifestyle as a dialectical process leads to the correct definition of its nature and essence. A healthy lifestyle reflects the Economic, localterritorial organization, spiritual world and self-awareness of a nation standing at a certain stage of social development, its distinctive life, its diverse forms, the activities of social development, which differ from other nationalities.

The deepening and enrichment of the process of a healthy lifestyle is associated with social factors. In particular, among them, the emergence of suitable living conditions takes a special place. Since the main idea of the national ideology consists in the restoration of a free and prosperous, free and prosperous life, it is quite clear that this is the main task of increasing the people's standard of living and ensuring a comfortable life. Today, the idea of prosperity has become the main goal of our national policy. For this purpose, major socioeconomic activities are carried out, such as strengthening the material and technical base of the prosperous life, deepening the processes of privatization, implementation of structural changes, wide involvement of foreign investments in production, application of advanced technologies.

\section{MATERIALS AND METHODS}

In this sense, it is extremely important to update and develop a healthy lifestyle. "Today, life itself requires us to develop an effective system for the formation of a professional, fast and efficient public service system, to open a wide road to new-thinking, enterprising, committed personnel," says [290]. Great attention is being paid to raising the national income of the country in order to socially strengthen our healthy lifestyle. In particular, the issue of state aid to the vulnerable, low-income strata of society is being positively addressed. Legal guarantees of a healthy lifestyle are being strengthened.

On the other hand, due to the social nature of production, the policy of Equalization of the lifestyle of different nationalities and nationalities in the country was a priority. This, of course, was nothing more than an unusual description of the issue of the originality of a healthy lifestyle. Any healthy lifestyle is 
practiced in a certain social environment, its owners find a certain national ground, consisting of an individual, a social layer, a national unit, classes that live and operate under conditions. On the other hand, a healthy lifestyle will be associated not only with material aspects, but also with the corresponding natural-geographical conditions, values, the manor of living, the way of living, the style of living of the people, the nation.

When thinking about the national content of a healthy lifestyle or the national lifestyle as a whole, it is necessary to shed light on the content of such concepts as "lifestyle", "life landscape", "national stylistics of behavior", which in our opinion is characteristic of certain social structures and strata that are divided by age. Of course, these concepts mean that the historical background of behavior inherent in a particular nation, representatives of ethnic unity, specific programs, rules and socially significant "templates"take place in the way of life.

One of the forms of a healthy lifestyle is a lifestyle. In our opinion, the manor of life is close to the concept of life Stylistics, its private appearance. It dates back to the distant centuries with its roots, and in the current conditions it is practiced ethnically mainly in the same environment and is part of the national label. From this point of view, we can see that the peoples of Central Asia, including the Uzbek people, have an important place in the healthy lifestyle of the elements that are defined by the Eastern labels and that they are manifested in the manners of manners. Although the culture of the Peoples has historically not been practiced alone, each of them has its own path of development and is composed as a national phenomenon. That is why the national forms of culture have become a tradition and have had a significant impact on a healthy lifestyle as a sustainable, holistic phenomenon.

In fact, the habits of many rituals in Zarathustra have been preserved until now in the way of life of our people. This place can be cited as an example of the fact that today's holidays associated with farming comply with the traditions of Zarathustra. "In the spring, in connection with the fertilization of the earth, he conducted such competitions as "field sowing", "crop growing", "crop harvesting", "Mother Earth", "threshing bunny", "harvest feast". Such holidays as Navruz, Mehrjon in Zoroastrianism, the emergence of a boychech in the spring, the opening of tulips, the flowering of almonds, the spring in general was considered a tantanum of the spirit of goodness, which caused great joy. Such traditions typical of the ancient cultural lifestyle today are celebrated in Khorezm and Bukhara in the style of "Red flower sayli", "Tulip sayli" in Fergana, Kokand and Tashkent suburbs, and in other places of "Sunbula sayli" in Chust in the style of "Boychechak sayli" [329].

In Uzbek families, there is a saying that children are brought up not only by parents, but also by relatives, sheep, neighbor, neighborhood. The formation of the moral image of young people has been greatly influenced by the environment in all periods. In families with many children, especially in rural areas, children are accustomed from a young age to work honestly, to educate their brothers, to help their parents, Ariesneighbor. "Big is small-when they meet, they greet each other and ask for a situation is also 
considered a high moral virtue. The fact that young people themselves come out when there is a ceremony in the House of Aries-Aries is also the result of National Education. Girls learned from parents, Aries-neighbor for the first time, not reading from books what is ibo, anxiety, humility, shame, chastity, or shame" [4-27].

Thus, the National signs of a healthy lifestyle are associated, first of all, with the history of the people, with its culture, language, traditions, customs and other spheres of spiritual life. The philosopher with the skirt I.With jabbarov's question, here follows the dialectical connection between the past and the present. Consequently," if the memory of the past is one of the important factors for spiritual and cultural development, the experience accumulated over the centuries is the most necessary ground in the perfection of man, in the historical development of elat and people " [5-259]. Hence, the nationality is the core of the people's historical experience, its social memory.

"It is very wrong and dangerous that in society there is a system of relations in which the interests of a separate group or separate territories prevail over common interests. says I.A.Karimov. - "Raising certain territorial differences to the level of absolute landing is the most dangerous mistake. The return of each individual to his national identity should not be determined by the perception of his own on a regional basis. A person should first of all feel himself as a citizen of Uzbekistan, and then as residents of the Khorezm, Samarkand or Fergana Valley. This situation does not in fact reduce the value and importance of "A delightful homeland", the place where a person was born, the country, his way of life and his own values, which each of us belongs to"[6-93].

Also, such a negative phenomenon as revenge on the blood with blood has already been eradicated, but in the appointment of people to career, negative phenomena such as bribery, localism, kinship, fellowship are still encountered, which always cast a shadow on the humanism and Justice nature of our healthy lifestyle. In some regions, especially in the southern regions of Uzbekistan, the phenomenon of Kalin has not completely disappeared. However, our people consider this phenomenon as a deviation from social norms.

\section{RESULTS}

The characteristics of a healthy lifestyle are inextricably linked with individual labor skills, methods and production experiences of people. This is naturally reflected in the experience of our people in the field of economic development (farming, cotton, livestock, etc.). In the analysis of the specific signs of our healthy lifestyle, it was stated above about the expediency of using the concept of "life mode", which is close to "lifestyle". In this sense, the concept of "married mode " can be applied not only to the healthy lifestyle of our people, but also to its current development.

Of course, the uniqueness in the sphere of marriage ukladi has historical roots. If we turn to the works of "Avesta", Farabi's "City of virtuous people", Joseph Khoshib's "Knowledge of salvation", Ahmad Yuknaki's "Hibatul haqayiq", Mahmoud Koshgari's "Devoni dictionary-Turkish", Kaykovus's "Kabusnamə", Alisher Navoi's "Prisoner-ul- 
qulub", Babur's "Baburname", along with many valuable information on the history of our people, he was married, had a family, and was We are faced with extraordinary peculiarities in the field of proceedings.

Our people are united by a diverse professionblind people, at the same time they are representatives of different nationalities and nationalities. In our Republic " along with the main Nation - Uzbeks, there are more than a hundred nationalities that have their own culture and traditions. Their share in the total population of the country exceeds 20 percent" [7-72]. A word about a healthy lifestyle borganda it is impossible to exclude this factor, of course.

When thinking about the sources, nature and character of a healthy lifestyle, the role of national consciousness and the national spirit can not be overlooked. The national consciousness reflects a complex mixture of social and ethnic aspects that evoke national and nation-wide communication and relations. The process of realizing that the people are connected and connected with a certain socioethnic unity takes place within the framework of national consciousness. This situation encourages knowledge of the native language and development, deepening of feelings of pride in the achievements of its people, preserving its advanced traditions, customs, culture. National consciousness ensures the individual's national identity, his lively connection with the nation, on this basis, his active participation in the formation and development of a healthy lifestyle.

National spirituality, national appearance, customer characteristics, manifested in the spiritual life of individuals also play an important role in the expression of the main characters and characteristics of a healthy lifestyle. Naturally, the socio-ethnic determinism of the national image does not remain without the realization of the nation as an expression of its identity and its influence on the way of life of people.

When thinking about the sources, nature and character of a healthy lifestyle, the role of national consciousness and the national spirit can not be overlooked. The national consciousness reflects a complex mixture of social and ethnic aspects that evoke national and nation-wide communication and relations. The process of realizing that the people are connected and connected with a certain socioethnic unity takes place within the framework of national consciousness. This situation encourages knowledge of the native language and development, deepening of feelings of pride in the achievements of its people, preserving its advanced traditions, customs, culture. National consciousness ensures the individual's national identity, his lively connection with the nation, on this basis, his active participation in the formation and development of a healthy lifestyle.

National spirituality, national appearance, customer characteristics, manifested in the spiritual life of individuals also play an important role in the expression of the main characters and characteristics of a healthy lifestyle. Naturally, the socio-ethnic determinism of the national image does not remain without the realization of the nation as an expression of its identity and its influence on the way of life of people.

The issue of the forms and levels of manifestation of a healthy lifestyle in the 
conditions of national independence has an important scientific and methodological significance. Under the influence of the abovementioned object and subject factors of a healthy lifestyle, there will be specificity in the sphere of life and individual relations. However, in our National way of life, not only are we archaic, but our people are absorbed into the colorful forms of their vital activity, they do not only represent a certain existence, but also bring it into the body. From the point of view of time, any phenomenon that has arisen recently in the field of life, even taken from other peoples, in accordance with its material and spiritual needs, can express the meaning of nationality. This is one of the most important legislations for the improvement of the way of life, which as a process requires further development in accordance with national originality, uniqueness and peculiarity.

The level of expression of a healthy lifestyle is not always the same and variable. It is associated with such factors as the state of change in the structure of society, its national composition, its natural-geographical features, demographic and migration processes, priority forms of economic activity.

As noted above, since the signs of a healthy lifestyle would be manifested through traditionalism, it is also possible that traditionalism can not at all times fully represent nationality. Indeed, today, many traditions in the technical sphere have lost their ethnic, national, regional character and are becoming increasingly universal. Such a feature can be seen at all levels in the sphere of production, distribution, turnover, consumption, as well as the ideology of national independence, which includes social relations, associated with traditional forms of state and legal activity.

In modern conditions, the most important aspects of a healthy lifestyle are manifested in ethnic stereotypes, which are formed under the influence of ethnopsychological factors and are directly connected with the ethnic traditions of life, in the words of the Daily system of behavior, the language of ethnographers. They are valid at the level of large-scale groups of individs and relatively people as a social phenomenon and perform a certain regularity function, which means that they constitute one of the source components of a healthy lifestyle.

In determining the legalities and forms of manifestation of a healthy lifestyle, it is necessary to take into account all omillarni that make up the social and cultural environment, whereas without this it is impossible to create a strategy of interaction that is carried out by people in a different social and individual sphere.

\section{CONCLUSION}

In place of the conclusion, it can be noted that the traditions, traditions of the people, the way of thinking of people. In this regard, such virtues as living by putting humanity above all things, being worthy of respect for other nationalities, other religious sects, kindness, which has become a priority in relation to Mother-Earth, great respect for science and Education, Labor constitute the basis of our healthy lifestyle, and in this regard, a healthy lifestyle of a person is conditioned by a certain social unity In other words, a healthy lifestyle is determined by the conditions of the object, 
as a result of which the object itself, as a process, will depend on certain legalities.

\section{REFERENCES}

1. Mirziyoyev Sh.M.The pillar of family and society, the interests of our life and the approval of our people is the highest assessment of our activities. 2-volume. T: Uzbekistan, 2018. - P. 476.

2. Mirziyoyev Sh.M. The consent of our people is the highest assessment given to our activities. 2-volume, - T.: Uzbekistan, 2018. - P. 90.

3. Karaboev U. Holidays of Uzbekistan. - T.: Uzbekistan, 2001. - P. 29-32.

4. Ibrahimov A., Sultanov H., Zhurraev N. A sense of Motherland.- T.: Uzbekistan, 1996. - P. 27-50.

5. Jabbarov I. Ethnography of the Uzbek people. - T.: Teacher, 1994. - P. 259

6. Karimov I.A. In the 21st century of Uzbekistan: the threat to security,the conditions of stability and guarantees of progress// security and sustainable. T.6volume.: Uzbekistan, 1998. - P. 93

7. Karimov I.A. In the 21st century of Uzbekistan: the threat to security, the conditions of stability and guarantees of progress// security and sustainable. T.6volume.: Uzbekistan, 1998. - P. 72. 